\title{
Article
}

\section{Exploring the MACH Model's Potential as a Metacognitive Tool to Help Undergraduate Students Monitor Their Explanations of Biological Mechanisms}

\author{
Caleb M. Trujillo, ${ }^{*+}$ Trevor R. Anderson, ${ }^{\ddagger}$ and Nancy J. Pelaez ${ }^{\dagger}$ \\ ${ }^{\dagger}$ Purdue International Biology Education Research Group (PIBERG), Department of Biological Sciences, and \\ łVisualization in Biochemistry Education (VIBE) Research Group, Department of Chemistry, Purdue University, \\ West Lafayette, IN 47907
}

Submitted April 3, 2015; Revised February 14, 2016; Accepted February 14, 2016

Monitoring Editor: Hannah Sevian

\begin{abstract}
When undergraduate biology students learn to explain biological mechanisms, they face many challenges and may overestimate their understanding of living systems. Previously, we developed the MACH model of four components used by expert biologists to explain mechanisms: Methods, Analogies, Context, and How. This study explores the implementation of the model in an undergraduate biology classroom as an educational tool to address some of the known challenges. To find out how well students' written explanations represent components of the MACH model before and after they were taught about it and why students think the MACH model was useful, we conducted an exploratory multiple case study with four interview participants. We characterize how two students explained biological mechanisms before and after a teaching intervention that used the $\mathrm{MACH}$ components. Inductive analysis of written explanations and interviews showed that MACH acted as an effective metacognitive tool for all four students by helping them to monitor their understanding, communicate explanations, and identify explanatory gaps. Further research, though, is needed to more fully substantiate the general usefulness of MACH for promoting students' metacognition about their understanding of biological mechanisms.
\end{abstract}

\section{INTRODUCTION}

Explaining complex living systems is a central objective of the life sciences that requires an understanding of their underlying biological mechanisms (van Mil et al., 2013). For life science educators, it is important to teach about biological mechanisms so that students may understand and explain such systems in biology. In addition to their value for science, mechanistic explanations in the classroom may help educa-

CBE Life Sci Educ June 1, 2016 15:ar12

DOI:10.1187/cbe.15-03-0051

*Address correspondence to: Caleb M. Trujillo (calebtru@gmail .com).

(C) 2016 C. M. Trujillo et al. CBE-Life Sciences Education (C) 2016 The American Society for Cell Biology. This article is distributed by The American Society for Cell Biology under license from the author(s). It is available to the public under an Attribution-Noncommercial-Share Alike 3.0 Unported Creative Commons License (http://creativecommons.org/licenses/by-nc-sa/3.0).

"ASCB ${ }^{\circledR}$ " and "The American Society for Cell Biology ${ }^{\circledR}$ " are registered trademarks of The American Society for Cell Biology. tors address recent calls for curriculum reform. For instance, in the Vision and Change in Undergraduate Biology Education report (American Association for the Advancement of Science [AAAS], 2011), leaders in biology and biology education reached consensus about the competencies that need to be addressed to improve undergraduate biology courses. Among these competencies, one goal was to help students develop an ability to generate and evaluate explanations. In this paper, we carefully examine how introductory biology students explained biological mechanisms using the MACH model (Trujillo et al., 2015) to guide their explanations.

Explaining is an indispensable skill for practicing scientists, but previous research results suggest that students face difficulties when explaining biological mechanisms. For instance, several studies note that secondary school students struggle to transcend multiple levels of biological organization (e.g., going from molecular to macroscopic levels) when explaining biological processes such as genetic mechanisms (Bahar et al., 1999; Marbach-Ad and Stavy, 2000; Duncan and Reiser, 2007). Similarly, when explaining genetics, 10th-grade students overlook the role of proteins in their biological explanations 
(Duncan and Reiser, 2007; Todd and Kenyon, 2015). At the undergraduate level, many students have difficulty explaining and representing mutation as a mechanism underlying genetic variation (Bray-Speth et al., 2014). Undergraduates are often taught transcription and translation, but they misinterpret symbols commonly used to represent these mechanisms (Wright et al., 2014). Reports have also documented that undergraduate students, when asked to explain the behavior of molecules, attribute cause at a variety of organizational levels (Talanquer, 2010) and often struggle to understand the undirected nature of molecular motion that underlies all cellular mechanisms (Garvin-Doxas and Klymkowsky, 2008). Across many age groups, students avoid providing mechanistic explanations when explaining "how" biological phenomena occur and instead resort to ultimate causes for explanations by explaining "why" phenomena occur (Abrams and Southerland, 2001). These explanatory and representational difficulties related to learning biological mechanisms are seen across a variety of instructional settings and student age groups.

Memory illusions could factor into difficulties seen in students learning biology. According to Roediger (1996), a memory illusion may occur any time a factor biases perception about memory so that individuals overestimate or underestimate their performance compared with their actual performance. Typically, memory illusions are attributed to a mismatch between memory and metamemory sometimes referred to as metacognition. Metamemory is defined as "the judgments, assessments, or commentaries that are made about memories or learning" (Dunlosky and Metcalfe, 2008, p. 349). Previous research has examined how metacognition interacts with academic performance to reveal that, on average, students tend to overestimate their academic performance (Kruger and Dunning, 1999). In fact, when disaggregated by performance groups, low-performing students tend to overestimate their performance more than high-performing students. This observation has been called the burden of dual incompetence, since the students who would most benefit from accurate judgments of knowledge tend to be unaware of their poor performance (Kruger and Dunning, 1999). These previous findings suggest that persistent memory illusions, unless addressed through targeted instruction, may especially impede learning for low-performing students. Nevertheless, memory illusions may not be the only factor that affects judgments of learning.

Explanations are susceptible to a unique type of memory illusion known as the illusion of explanatory depth, which occurs when "people feel they understand the world with far greater detail, coherence, and depth than they really do" (Rozenblit and Keil, 2002, p. 522). Through a series of studies, it was revealed that subjects tend to overestimate how well they can explain natural phenomena but can more accurately judge their knowledge of facts, procedures, and narratives (Rozenblit and Keil, 2002). The presence of hidden causes and hierarchical structures are two factors of an explanation that may contribute to this illusion (Rozenblit and Keil, 2002). When biology students are learning to explain living systems, these factors may contribute to an overestimation of their understanding since biological mechanisms are explained across multiple levels of biological organization (hierarchies) and often contain hidden activities.

There are three key issues pertaining to teaching and learning about biological mechanisms: 1) students face a range of difficulties when asked to explain biological mechanisms; 2) students are at risk of developing illusions of explanatory depth due to the hierachical and hidden nature of biological mechanisms (Rozenblit and Keil, 2002); and 3) low-performing students may have exaggerated illusions that, unless reduced, may interfere with their academic growth during a course (Kruger and Dunning, 1999). We identified a need to overcome the abovementioned difficulties and illusions with instructional tools that would support the development of students' explanatory and metacognitive skills. Our research goal was to explore a new teaching intervention to improve the explanatory abilities of students so that they may learn to explain biological mechanisms competently and be able to monitor and control their own learning. Toward this goal, we deployed our previously developed MACH model (Trujillo et al., 2015) in a teaching intervention.

The MACH model is a representation of the components included by biologists when they explain biological mechanisms. Previously, we interviewed practicing biologists of different subdisciplines and identified four themes present in their explanations (Trujillo et al., 2015). The data and subsequent analysis informed development of a model with four components that seven biologists included when explaining their familiar mechanisms: Methods (M), Analogies (A), Context $(\mathrm{C})$, and How $(\mathrm{H})$ components (detailed below and defined in Table 1). The Methods component includes references to the research tools, data, and procedures used to understand a given mechanism. As a second component, biologists incorporate Analogies, including visual representations like models and diagrams, or they provide a narrative story, perhaps by anthropomorphizing the activities of entities or using metaphors to connect mechanisms to everyday experiences. The Context component includes biological and social contexts to situate the mechanism in terms of its importance. For example, some biologists embed their explanations in a social setting like disease when explaining, whereas others contextualize around the functions of an organism, taxon, cell type, or other biological setting. All the biologists we interviewed focused heavily on How the mechanism workshow the component entities of the biological phenomenon interact at the molecular, microscopic, and macroscopic levels to produce detectable changes in state, activities, and organization in space and over time (Trujillo et al., 2015).

When they were probed to give a complete explanation about a biological mechanism, biologists from a range of subdisciplines integrated the four MACH components into their explanations. Taken together, the MACH model represents the components practicing biologists included when they explained biological mechanisms. Each component can be used as a theoretical construct (Clark and Watson, 1995) to analyze the content of biological explanations. In addition, and of relevance to the present paper, the MACH model could potentially guide learners to examine mechanisms in biology (Trujillo et al., 2015).

\section{RATIONALE AND RESEARCH QUESTIONS}

To address the difficulties and illusions with explanations that may be detrimental to learning, we identified an opportunity to use the MACH model as a guiding framework to teach students the components the interviewed biologists 
Table 1. Operational definitions of the MACH components ${ }^{a}$

MACH components

Description with examples

Methods: The tools, data, or procedures used to generate evidence that informs the explanation and qualifies or limits the generalizability of interpretations.

Procedures include protocols or processes such as experimental design and transgenic comparison. Tools include instruments used to observe, visualize, and record evidence such as X-ray crystallography, devices, microscopes, and oscilloscopes. Data refers to quantitative measurements, variable properties, observations, and physical properties of the system, such as biomolecules and cellular environment, as well as the findings from experiments.

Analogy: The stories and analogies that make sense of and relate to a purpose for the mechanism with formal analogies, models, or narrative forms.

Formal analogies are explicit analogies (metaphors or similes) to represent a similar function or property and are evident by language such as "An ion channel behaves like a door to a room" and "lock and key." Narrative forms are informal ways of explaining that include: storytelling; teleology; reverse causality; need-based, environmentally deterministic, and purposed formulations; and forms that attribute human or animal characteristics to nonanimal entities (anthropomorphizing). These noncausal statements attribute molecules with an experience that goes beyond collisions, binding, and interactions, such as "the cell runs out of energy," "hyperactive," and "signals." Models are visual (nontext) representations such as arrow diagrams, graphs, mathematical models, and chemical equations.

Context: The biological context or social concern, which connects the explanation to a situation where it can be applied and makes it possible for its importance to be fully understood.

Biological contexts establish biological importance by relating the explanation to a distinct organelle, cell type, organ, and so on, or connecting to evolutionary history. Social contexts depict a human or societal concern, and examples include disease, health, or other social issues.

How: A description of how the component entities of a biological phenomenon interact at the molecular, microscopic, and macroscopic levels to produce detectable changes in state, activities, and organization in space and over time.

Entities are the living and physical components of the system, such as biomolecules, proteins, organelles, cells, and so on, and these entities interact by binding and inhibiting and have states. States are in the form of modifications, isoforms, or specific confirmations, such as open confirmation, phosphorylated, hyperpolarized, and bound states. These states are variable properties of the entities, and when the states change, activities occur; enzymes activate from "off" to "on" or proteins becomes phosphorylated. Entities and activities exist at several levels of biological organization. They are organized by timing and order, which are depicted by rate, frequency, sequence, or causal chains ("X induces $Y^{\prime \prime}$ ). The spatial arrangement of entities and activities also matters, such that localization like "inside the cell," structure, orientation, connectivity, compartmentalization, distance, and conformation are identified.

aModified from Trujillo et al., 2015.

used when they explained mechanisms. Rather than opting for a generalizable study, we wanted to specifically gain insight into how a few undergraduate life science students would learn to explain biological mechanisms using the $\mathrm{MACH}$ model as an educational tool. In particular, we asked the following research questions:

1. How do written explanations elicited from two selected students from an introductory biology class represent the components of the $\mathrm{MACH}$ model before being taught about it?

2. After an in-class teaching intervention and guided practice using components of the $\mathrm{MACH}$ model were these same two students using the MACH model to explain biological mechanisms?

3. How and why did four interviewed students from the class think the MACH model was useful?

Our aim in answering these research questions was to explore the potential of the MACH model, which is an expert-derived component model, as a learning tool for the undergraduate biology classroom. Further research would, of course, be required to then gauge the generalizability of this tool across larger groups of students.

\section{METHODS}

An exploratory case study was conducted to investigate the explanations and experiences of students before and after the teaching intervention. The intervention was designed to help undergraduate biology students use the $\mathrm{MACH}$ model to guide their explanations. The $\mathrm{MACH}$ components Methods, Analogies, Context, and How operated as constructs that represented four components that experts use to explain mechanisms in biology. Although uncommon in biology education, case study designs can vary widely to meet different purposes, such as theory building, intervention design, and evaluation (Baxter and Jack, 2008). According to Flyvbjerg (2006), case study research, often reported in a narrative form, can provide knowledge that is falsifiable, context-dependent, and generative. An exploratory case methodology was appropriate for this study due to the fact that multiple data sources were used, no single outcome was anticipated, participants' perspectives were considered, previous research on the use of MACH in the classroom was lacking, and due to this lack of knowledge on the subject, both direction and theory were needed for future research (Tellis, 1997; Baxter and Jack, 2008).

\section{Student Population}

Research was conducted in a classroom setting with follow-up interviews in an office at a large midwestern university in the United States. The course in which the teaching intervention was implemented was the second in a series of four lower-division courses for students who are biology majors. The course was a lecture course without a concurrent laboratory component. The 56 students enrolled in 
the course were primarily freshmen and sophomores. To conduct the multiple case study, we recruited four student volunteers for in-depth interviews about their explanations before and after a teaching intervention. To recruit students, an education researcher not associated with this project came at the end of a class period and collected contact information from students who volunteered to participate. From this pool of volunteers, two students who performed well using the MACH model and two who faced difficulties were recruited for interviews to understand how and why they used the MACH model and to understand the content of their explanations before and after the intervention. Each pair included a male and a female. Students were recruited and all data were collected according to protocols approved by the university's institutional review board (protocol nos. 1306013717 and 1203012039).

\section{Design of the Intervention}

The purpose of the teaching intervention was to aid students in structuring their explanations according to the $\mathrm{MACH}$ components and to guide their learning and construction of explanations about biological mechanisms. Toward this end, a teaching intervention was planned and implemented using a modified version of the MACH model. The modification entailed developing a paper-based physical model in the form of a foldout tetrahedron in which each vertex of the tetrahedron represents a different $\mathrm{MACH}$ component. This tetrahedral model is available online (Trujillo et al., 2014).

At the start of the intervention, the students were assigned in-class worksheets and told to work individually. Table 2 contains prompts that were given to the students. During the intervention, students received a 50-min guest lecture from C.M.T. The goals of the lecture were to help students practice using the MACH model to develop an ability to evaluate their knowledge of explanations, to analyze an explanation and a video, and to construct an explanation. The lecture followed the topic of neurons and action potentials and focused on vesicle trafficking. The lecture was conducted in four steps. First, students watched a molecular animation of vesicle trafficking (Liebler, 2007). Second, students wrote their own explanation about how vesicles traffic. Third, the students were instructed about each of the MACH components, using examples from the assigned reading, as detailed in the next paragraph. Finally, students folded the tetrahedral model and were instructed that a complete explanation would connect all four vertices. Throughout each step, students followed a worksheet and evaluated their knowledge about vesicle trafficking by answering clicker questions.

Along with the intervention, students were provided with a problem set (Table 2) as homework to practice identifying the MACH components, a summary document to read about a 2013 Nobel Prize (Zierath and Lendahl, 2013), and a review article to read about vesicle trafficking (Bonifacino and Glick, 2004). After analyzing the articles, students created their own written explanations of vesicle trafficking as part of their homework problem set. The students were given many opportunities to practice using the $\mathrm{MACH}$ model, since several later course assignments about molecular and cellular mechanisms also required students to write explanations specifically informed by the MACH model. For instance, when students did research on a topic of their choice by collecting original research articles, they were required to use the MACH model to inform what to include about the mechanism and to present their findings as posters presented individually or in small groups at the end of the course.

\section{Evaluating Student Explanations}

To understand the MACH model components students used in their explanations before and after the intervention and to address research questions 1 and 2, we examined the explanations produced by students in response to the assignments listed in Table 2.

Data Collection. Explanations were collected at multiple time points, including before and after the intervention (Table 2). These artifacts included an explanation from exam 2 before the intervention, an explanation from the in-class worksheet during the intervention, two explanations from homework problem sets after the intervention, one oral explanation from the interview, and explanations from exams 3 and 4 (one each) after the intervention. The prompts used in exams 2, 3, and 4 were similar, since students were asked to write one-page essays to explain a detailed mechanism and to draw and label diagrams appropriate to their explanations on each exam. The three prompts differed in that exam 2 asked students to explain a mechanism related to a plant cell's response to light, exam 3 asked students to structure an explanation using the MACH model to explain how a retinal photoreceptor cell responds to light, and exam 4 asked students to use MACH to explain any mechanism of choice that was learned during the course. All exam prompts were available $1 \mathrm{wk}$ in advance of examination. Apart from the research presented, these prompts were used to evaluate students' course performance. Teaching staff graded student responses for correctness in a manner that differed from the analysis presented in the Results section. All relevant prompts of exams and other data sources used in this study are listed in Table 2 to show the many opportunities students had to use the MACH model, to account for the process of data collection, and to provide details for potential replication of the study.

Data Analysis. To analyze these data in order to understand what the two students included before the intervention and, in so doing, address research question 1, we extracted segments of text from the exam 2 explanations that fit the operational definitions of the MACH model components (Table 1). In a similar manner, written explanations made after the teaching intervention were examined to address research question 2 in order to understand use of the MACH components in guiding written explanations after the teaching intervention. Written responses from exams 3 and 4, the problem sets, and oral explanations collected during interviews were also analyzed for the use of MACH components.

\section{Student Interviews}

To corroborate our analysis and to understand patterns expressed by students about how and why the MACH model was useful, if at all, we interviewed four students of different performance levels about how they experienced and used the MACH model throughout the semester. These data helped to address research questions 2 and 3. 
Table 2. Topics of mechanistic explanations made by Felix and Petunia in response to assignments before, during, and after the MACH model intervention

\begin{tabular}{|c|c|c|c|}
\hline $\begin{array}{l}\text { Timing and } \\
\text { source }\end{array}$ & Assessment prompt & $\begin{array}{l}\text { Felix's } \\
\text { mechanisms }\end{array}$ & $\begin{array}{l}\text { Petunia's } \\
\text { mechanisms }\end{array}$ \\
\hline \multicolumn{4}{|c|}{ Before intervention } \\
\hline Exam 2 & $\begin{array}{l}\text { Choose any ONE specific example of a protein conformational change that plays } \\
\text { an important role in the regulation (control) of a response to light by a plant } \\
\text { cell. Write a maximum 1-page essay to explain the mechanism of your selected } \\
\text { process. Draw and label a diagram as part of your explanation. Describe all } \\
\text { the details you know about the phenomenon. }\end{array}$ & $\begin{array}{l}\text { Phototropism } \\
\text { (Figure 1) }\end{array}$ & $\begin{array}{l}\text { Activation of } \\
\text { phytochrome } \\
\text { (Figure 2) }\end{array}$ \\
\hline \multicolumn{4}{|c|}{ During intervention } \\
\hline $\begin{array}{l}\text { In-class } \\
\quad \text { worksheet }\end{array}$ & $\begin{array}{l}\text { Hand-write a paragraph to explain how vesicle trafficking occurs within the cell. } \\
\text { Draw and label a diagram as part of your explanation. Describe all the details } \\
\text { you know about the phenomenon. }\end{array}$ & $\begin{array}{l}\text { Vesicle } \\
\text { trafficking }\end{array}$ & Vesicle trafficking \\
\hline \multicolumn{4}{|c|}{ After intervention } \\
\hline Problem set A & $\begin{array}{l}\text { Write a maximum 1-page essay to explain the mechanism of how vesicles traffic } \\
\text { within a cell. Draw and label a diagram as part of your explanation. Describe } \\
\text { all the details you know about the phenomenon. Use the MACH model } \\
\text { (Trujillo et al., 2015) to guide and structure the content of your explanation. } \\
\text { Make it clear which parts of your explanation correspond to each component } \\
\text { of the model. }\end{array}$ & $\begin{array}{l}\text { Vesicle } \\
\text { trafficking }\end{array}$ & Vesicle trafficking \\
\hline Problem set B & $\begin{array}{l}\text { Generate an original explanation about a biological mechanism of your choice } \\
\text { using the MACH model mechanism components handouts as guidelines. }\end{array}$ & $\begin{array}{l}\text { Regulation of } \\
\text { guard cells }\end{array}$ & $\begin{array}{l}\text { Related to thalido- } \\
\text { mide (Figure } 4 \text { ) }\end{array}$ \\
\hline Exam 3 & $\begin{array}{l}\text { Choose any ONE specific example of a mechanism that plays an important role } \\
\text { in the response of a photoreceptor in the retina to light. Write a maximum } \\
\text { 1-page essay to explain the mechanism of your selected process. Draw and } \\
\text { label a diagram as part of your explanation. Describe all the details you know } \\
\text { about the phenomenon. Use the MACH model (Trujillo et al., 2015) to guide } \\
\text { and structure the content of your explanation. Make it clear which parts of } \\
\text { your explanation correspond to each component of the model. }\end{array}$ & $\begin{array}{l}\text { Phototransduction } \\
\quad \text { (Figure } 3 \text { ) }\end{array}$ & Phototransduction \\
\hline Interview & $\begin{array}{l}\text { Today I would like you to talk about cellular mechanisms. Let's take a moment } \\
\text { to think. Take your time and start thinking about these types of processes. } \\
\text { Take as much time as you want, don't rush, just relax and think about them } \\
\text { for a while. Try to imagine it; mechanisms inside the cell, think about every- } \\
\text { thing you know about what these are and how do they work. OK, what are } \\
\text { you thinking about now? Tell me slowly and clearly, take your time (modified } \\
\text { from Schönborn and Anderson, 2009; Trujillo et al., 2015). }\end{array}$ & $\begin{array}{l}\text { Regulation of } \\
\text { guard cells }\end{array}$ & $\begin{array}{l}\text { Related to } \\
\text { thalidomide }\end{array}$ \\
\hline Exam 4 & $\begin{array}{l}\text { Choose any ONE specific example of a mechanism that you learned about this } \\
\text { semester. Write a maximum 1-page essay to explain the mechanism of your } \\
\text { selected process. Draw and label a diagram as part of your explanation. De- } \\
\text { scribe all the details you know about the phenomenon. Use the MACH model } \\
\text { (Trujillo et al., 2015) to guide and structure the content of your explanation. } \\
\text { Make it clear which parts of your explanation correspond to each component } \\
\text { of the model. }\end{array}$ & $\begin{array}{l}\text { Mechanism of } \\
\text { apoptosis }\end{array}$ & $\begin{array}{l}\text { Related to } \\
\text { thalidomide } \\
\text { (Figure 5) }\end{array}$ \\
\hline
\end{tabular}

Interview Protocol. Four volunteer students were selected for interview to help us understand how students of varying success used the MACH model and why students thought it was useful. Interviews were semistructured to collect the following types of data from each student:

- Background information about the student;

- An oral explanation of a mechanism of choice in response to the interview prompt in Table 2;

- A discussion of the student's experiences with the MACH model using guiding questions such as "What has your experience been like around the MACH model?" and "Do you use the MACH model, and what kind of outcomes came from using it?";

- A debriefing involving student reflection on artifacts made by the student throughout the semester with ques- tions like "Would you like to talk me through how things have changed across your work? I have some examples of work you have done."

Audio recordings, student-made artifacts, and interviewer notes were gathered for analysis.

Data Analysis. Audio recordings from the student interviews were transcribed. The transcripts, notes, and artifacts were analyzed using a general inductive approach (Lincoln and Guba, 1985; Thomas, 2006) to understand each student as an individual case. Additionally, cross-cutting themes were organized around the data and, where possible, were systematically related across the participants. If a particular idea was well supported across interviews by its prevalence and its degree of support, it was identified. Once several 
ideas related to research question 3 were identified, assertions drawn from the analysis were named, defined, and tested. To establish credibility (Lincoln and Guba, 1985), we tested each assertion by organized supporting and disconfirming evidence (in the form of quotes, notes, and artifacts) and weighed the prevalence and strength of the evidence. By analyzing these four students' use of the MACH components throughout the semester and by interviewing the students to understand their experiences with and their reflections about the MACH model and the intervention, we hoped to better understand why a student would find the MACH model useful. This analysis allowed us to address research question 3. Once the results had been documented, member checking was performed with one student (named Felix below) who was required to confirm or refute the authenticity of the documented findings. Students were named with pseudonyms to protect their identities.

\section{RESULTS}

In this paper, we present two selected cases in rich detail to address research questions 1 and 2 and excerpts from interviews with four students to address research question 3 . The two students presented in detail are Felix, a student who initially struggled to use the MACH components in his explanations, and Petunia, a student who was immediately able to incorporate the components into her explanations. The two cases presented are critical cases (Flyvbjerg, 2006), meaning that, if the intervention was useful for these two students whose initial performances differed, then it may be useful for other students. Conversely, if the MACH model was not useful for both participants, then it would most likely not be useful for students from different performance levels. We present how these two students vary in their adoption of the MACH model. By reporting such contrasting cases, we hoped to be able to highlight the important commonalities and differences between the two students. Analysis of the student explanations across many data sources (Table 2) revealed patterns that were found across all four case study participants. Quotes from Felix and Petunia provided below illustrate these patterns.

When the qualitative data are presented, the source of each excerpt is indicated by the participant name followed by the data source and line number, all in parentheses. For example, "Felix 2: 138-141" means that the excerpt came from Felix's second interview, between lines 138 and 141 of the transcript. Many of the prompts allowed students to select a mechanism of their choice, so some students repeated topics when explaining.

Felix was selected for the interview because his explanation scored below the median on his first exam after the $\mathrm{MACH}$ teaching intervention. By talking to Felix, we hoped to understand MACH from the perspective of a student who faced challenges when asked to explain mechanisms using the MACH model. Felix had extensive laboratory research experience beyond anything known by most other students at his level. As a first-year undergraduate student majoring in plant sciences, he enrolled in the present biology course in case he later decided to change his major to biology. While he had always been a good student, he felt the other students in this class were ahead of him academically. As a " $\mathrm{B}$ " student, he was competent and hardworking. What made Felix a unique student was his previous $450 \mathrm{~h}$ of research experience in two different plant science laboratories over three summers.

Petunia was a high-performing student who was selected because she was among the top students in the class. Her explanations scored above the median. We selected Petunia for a case study so as to understand what a student with high marks could gain from using the MACH model. Petunia was a first-year undergraduate student who excelled in her course work as a pre-pharmacy student. Growing up in a nearby developing metropolitan suburb, she had experienced many educational opportunities. For example, she had completed multiple Advanced Placement courses before attending the university. Although she lacked research experience as a first-year college student, she was considered to be a top student and a source of information by her peers.

\section{How Do Student Explanations of a Mechanism Represent the Components of the MACH Model before the Intervention?}

To address research question 1, we analyzed exam 2 responses from two volunteer students of different levels of performance. Felix drew some diagrams (Figure 1) and wrote the following response to exam 2 about phototropism in plants:

When blue light hits phototropin, or PHOT1, the pro-
tein changes its shape, opening a protein kinase site
that begins a signal transduction cascade. This cascade
eventually signals the movement of the plant hormone
auxin. Based on the direction the light is coming from,
the auxin will move away from the light source, mov-
ing from cell to cell using polar transport until it reach-
es the far end of the plant stem. The higher concentra-
tion of auxin on the opposite side of the plant stem will
cause the cells there to elongate more rapidly than the
lit side. This in turn causes the stem to curve toward
the light in a phenomenon called phototropism. (Felix,
exam 2)

The detailed analysis of the MACH components present in his explanation is indicated in Table 3. Based on Felix's written explanation, all MACH components are represented, but the Context and Methods components were rather superficial. Felix's explanation began by showing evidence of the How part of the mechanism by connecting the activities and organizations of molecular and cellular entities in a mechanistic manner in an attempt to explain how a plant stem curves toward a light source. Figure 1 provides evidence of Felix's use of Analogy. His model shows that varied light conditions alter the movement of auxins between plant cells. While he included an observation, a robust Methods component is lacking from this explanation. Although his drawing illustrates an experimental and control treatment with plant stems in the presence and absence of light, the tools and procedures used to gather evidence for auxin as a signal are not included to fully communicate how scientists understand the mechanism of phototropism. Additionally, the Context component is represented by a generic context of a plant cell, which was given in the prompt. A better 


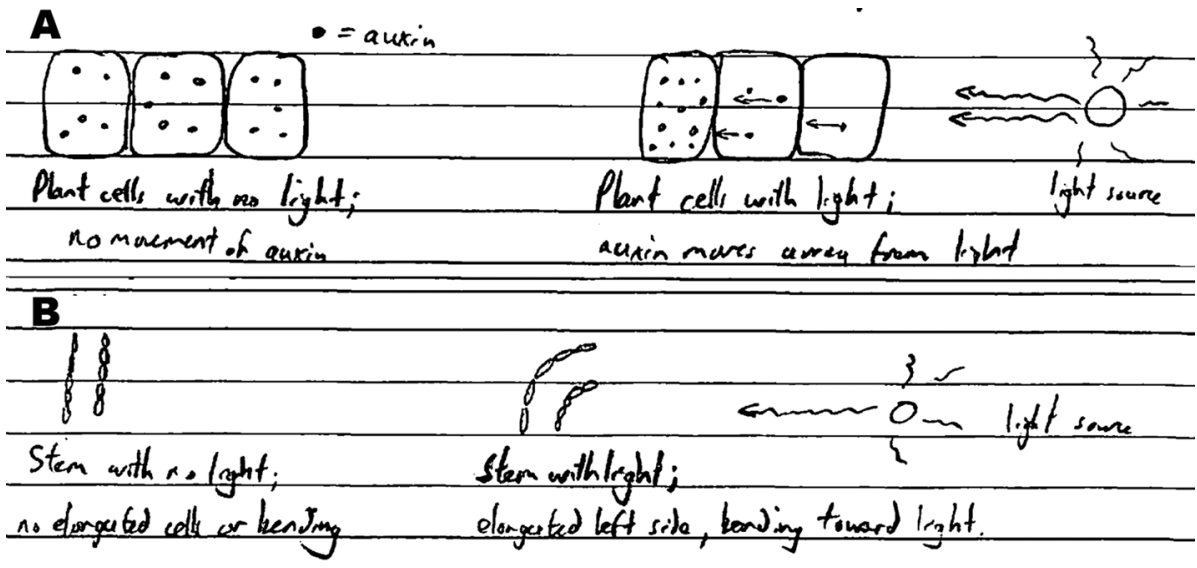

Figure 1. Drawings made by Felix as part of his exam 2 explanation to address phototropism in plants. Panel A indicates the movement of auxin within the plant cell under different light conditions. Panel B indicates the elongation and bending of the plant stem under different light conditions. context statement would have connected to the importance of phototropism, to its relationship to society, or by naming a particular organism. The MACH components are evident in Felix's exam 2 explanation, but using the model as a lens illustrates specific areas that could better align with the expert-derived components.

Petunia did not include all the MACH components before the intervention. Her exam 2 explanation indicated use of $\mathrm{A}, \mathrm{C}$, and $\mathrm{H}$, but she did not include the $\mathrm{M}$ component for her explanation of phytochrome activity in flowering plants. Unlike Felix, she wrote a full-page explanation about phytochrome in plants. The following segment indicates the rich detail used by Petunia:
Phytochrome molecules exist in the cytosol of plant cells and are often found in higher concentrations in the growing parts of young plants. These phytochromes consist of 2 subunits which each have a chromophore that absorbs light photons. In its inactive, ground state, phytochrome is in the Pr form, which consists of a cis-conformation of the chromophore and has the capability to absorb red light. When red light photons are absorbed, the chromophore changes from cis to trans and becomes the Pfr form capable of absorbing far-red light. This form is biologically active, and it induces a conformational change in the phytochrome protein that exposes two active regions. One region of the phytochrome protein becomes a kinase. This part phosphorylates another region of the phytochrome protein,

Table 3. Felix and Petunia's varied use of the MACH components in exam 2 explanations made before the intervention

\begin{tabular}{|c|c|c|}
\hline Student & $\begin{array}{l}\text { MACH } \\
\text { components }\end{array}$ & Example excerpt with subcomponents indicated within brackets \\
\hline Felix & $\begin{array}{l}\text { Methods } \\
\text { Analogies } \\
\text { Context } \\
\text { How }\end{array}$ & $\begin{array}{l}\text { "This in turn causes the stem to curve toward the light in a phenomenon called phototropism [data observation]." } \\
\text { "This cascade eventually signals movement of the plant hormone auxin [narrative]." Figure } 1 \text { diagrams [model] } \\
\text { "... on the opposite side of the plant stem... [biological context]" } \\
\text { "When blue light hits phototropin [interaction], or PHOT1 [entity], the protein changes its shape [state, activity], } \\
\text { opening a protein kinase site that begins a signal transduction cascade. This cascade eventually signals the } \\
\text { movement of the plant hormone auxin [entity, activity]. Based on the direction the light is coming from, the aux- } \\
\text { in will move away from the light source [activity, organization], moving from cell to cell using polar transport } \\
\text { until it reaches the far end of the plant stem [activity, organization]. The higher concentration [state] of auxin on } \\
\text { the opposite side of the plant stem will cause [interaction] the cells there to elongate [activity] more rapidly than } \\
\text { the lit side [activity, organization]." }\end{array}$ \\
\hline \multirow[t]{4}{*}{ Petunia } & Methods & Absent \\
\hline & Analogies & $\begin{array}{l}\text { "This form is biologically active, and it induces a conformational change in the phytochrome protein [narrative]." } \\
\text { Figure } 2 \text { diagrams [model] }\end{array}$ \\
\hline & Context & $\begin{array}{l}\text { "Phytochrome molecules exist in the cytosol of plant cells [biological context]." } \\
\text { "The phytochrome changes conformations in response to red or far-red wavelength, low energy light and } \\
\text { contributes to flowering timing and regulation in angiosperms [biological context]." } \\
\text { "Depending on whether the plant is a short day or a long day plant, it would require higher Pr or Pfr forms } \\
\text { respectively [biological context]." }\end{array}$ \\
\hline & How & $\begin{array}{l}\text { "Phytochrome molecules [entity] exist in the cytosol of plant cells and are often found in higher concentrations } \\
\text { [state] in the growing parts of young plants. These phytochromes consist of } 2 \text { subunits which each have a } \\
\text { chromophore [entity] that absorbs [interaction, activity] light photons [entity]. In its inactive, ground state, } \\
\text { phytochrome is in the Pr form [state], which consists of a cis-conformation [state] of the chromophore and has } \\
\text { the capability to absorb red light. When red light photons are absorbed [interaction], the chromophore changes } \\
\text { from cis to trans [activity] and becomes the Pfr form [state] capable of absorbing far-red light [activity, orga- } \\
\text { nization]. This form is biologically active, and it induces a conformational change in the phytochrome protein } \\
\text { [activity] that exposes two active regions [organization]." }\end{array}$ \\
\hline
\end{tabular}


A

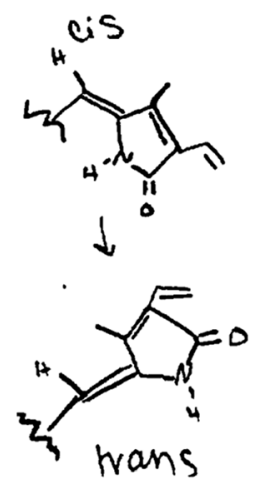

B

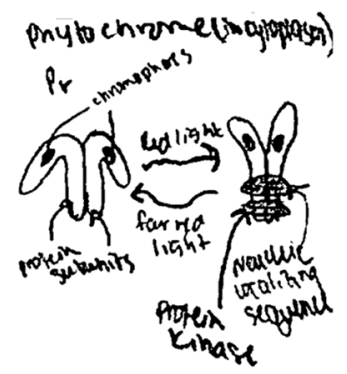

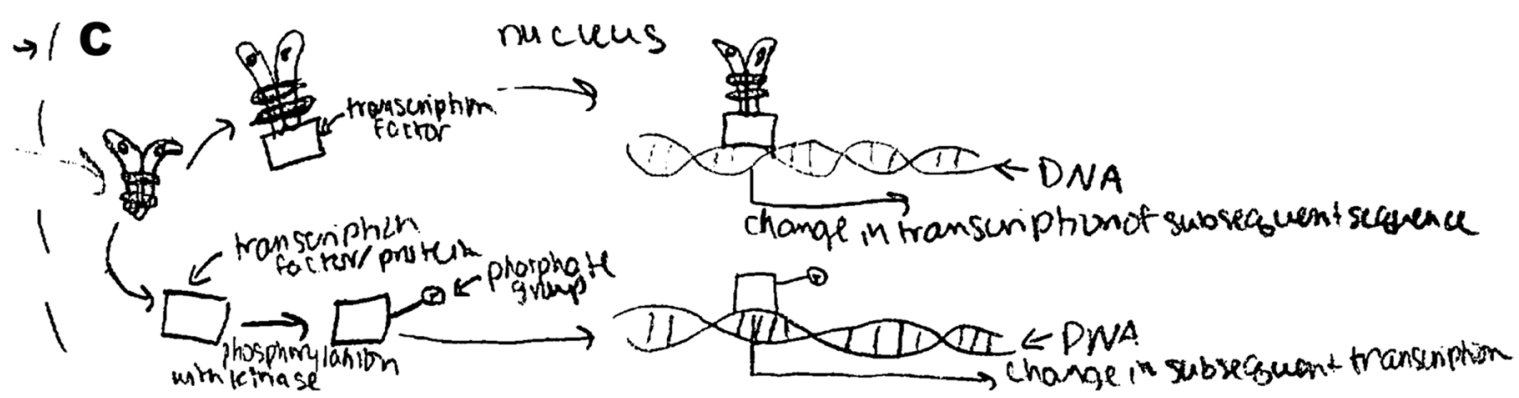

Figure 2. Drawings made by Petunia as part of her exam 2 response to explain the activation of phytochrome in plants by light. Panel A indicates a chemical change from the cis to trans configuration of the chromophore. Panel B is a model of the phytochrome protein changing conformation and protein domain exposure depending on whether it is exposed to red or far-red light. Panel C shows a model of activated phytochrome entering the nucleus and affecting transcriptional regulations.

which contains an exposed serine residue. When this residue is phosphorylated a nuclear localization sequence is exposed. (Petunia, exam 2)

Analysis of the components represented in her work is presented in Table 3. Clearly, Petunia gave explicit and extensive details of many organized entities and activities to explain the underlying mechanism of flowering and germination. So the How component was well represented. Although her use of Analogy was limited in her writing, Figure 2 indicates multiple models she used to depict phytochrome's chromophore structure, its activation by light, and its activity within the nucleus. In contrast to Felix, her Context component was detailed, because she indicated three different ways the mechanism was situated within the biological context, both within the plant and in terms of how different kinds of plants respond to their surroundings. Like Felix, her Context was lacking any social context (Table 3). Furthermore, the exam 2 explanation elicited from Petunia indicated that some MACH components were deeply represented while the Methods were absent.

Using $\mathrm{MACH}$ as a lens allowed us to identify where the explanations were aligned with and diverged from the expert-derived components. The two student explanations written for exam 2 before the intervention showed variable representation of the $\mathrm{MACH}$ components. While both responses showed evidence of $\mathrm{A}, \mathrm{C}$, and $\mathrm{H}$, the quality of the components was drastically different among the students. Felix's Context component was superficial, and Petunia's visuals were the bulk of her Analogy. Neither Petunia nor
Felix was thorough in his or her incorporation of the Methods component into the explanation.

\section{Were Students Using the MACH Model to Explain Biological Mechanisms after the Intervention?}

The artifacts and interactions collected from Petunia and Felix were used to address research question 2, to understand how students used MACH after the intervention. The findings suggested that they used all MACH components to structure their explanations, but Felix and Petunia differed in how quickly each was able to inform his or her explanation with MACH components. Petunia was able to immediately use all four components after the intervention, whereas Felix required extensive practice with the MACH model before successfully using the components.

Felix. After the intervention, Felix struggled to use the Methods component when explaining his chosen mechanism. During exam 3, the first test after the intervention, Felix explained how a photoreceptor responds to light when he wrote the following:

Rhodopsin is an important photoreceptor that, along with the other opsins, has allowed humans and other organisms [to] create visual images. This multi-step response to light begins with a photon being absorbed by rhodopsin, after which a heterotrimeric G-protein called transducin is catalyzed. When transducin is catalyzed, cGMP-specific phosphodiesterase, or PDE, is activated. PDE "eats" up cGMP, which are normally bound to $\mathrm{Na}^{+}$channels to keep them open. Therefore, 
cGMP levels are low in the presence of light, but return to higher levels in the dark, as shown in Figure [3A]. This cascade of events in a network of photoreceptors leads to the creation of an image. When light is not focused on the central point, however, lateral connections inhibit the maximum potential of an eye to see. How the cascade works is show in Figure [3B]. (Felix, exam 3)

Felix explained step by step how the entities are sequentially activated in the photoreceptor (How) and how this mechanism relates to vision in humans and other organisms (Context). Using Analogy, he generated visuals (Figure 3) and personified an enzyme with an ability to eat. He indicated cGMP level fluctuations, which corresponds to a variable property of the cell, but the representation and explanation were not thorough enough to communicate a methodological understanding of how researchers studied the mechanism (Figure 3A). Felix acknowledged this when shown his explanation:

I don't think I did too well on this.... I talk about how photoreceptors work and how it relates to certain secondary messengers, and a lot of this is just How. Actually, all of this is how it works and almost none of it is Methods. There is a little bit of Context, and there is like no Methods in this at all, which is kind of like what I was talking about with the class and not having been taught how certain things were found. (Felix 2: 459-466)

Felix affirmed that the Methods are a weaker portion of his written explanation, but he also felt as though the instructor did not spend enough time explaining how scientists resolved the phototransduction mechanism. He stated,

\begin{abstract}
Methods were the hardest part especially when we started out because we just weren't given that.... Like we would talk about, for instance, opsin and light receptors and mammalian eyes and we would know how they worked. But, we weren't given any information about like how people found out it worked that way.... A lot of people [students] I feel like struggled [on the exam] trying to get the Methods because all we reviewed was stuff in the lecture and from the book and there wasn't too much of the Methods in that. But once we got to independent research parts [the poster] where you look up papers and stuff, you know, it was a lot easier to find the Methods that way because they list it out for you. (Felix 2: 87-98)
\end{abstract}

As a student, he commented that he was not taught to include components like Methods in his explanations of mechanisms. Despite this, Methods were presented during lectures linked to mechanistic explanations, but he did not recognize this link. In fact, Felix's drawing appeared similar to the research methods represented in a lecture slide that contained a diagram of a voltage-sensing microelectrode inserted into a photoreceptor cell and data from an experiment in which measured membrane potential changed in response to different light intensities. The text on the slide asked students to "Sketch a graph of cGMP levels in the cytoplasm when this vertebrate photoreceptor cell responds to light." In the interview excerpt, Felix noted that he could

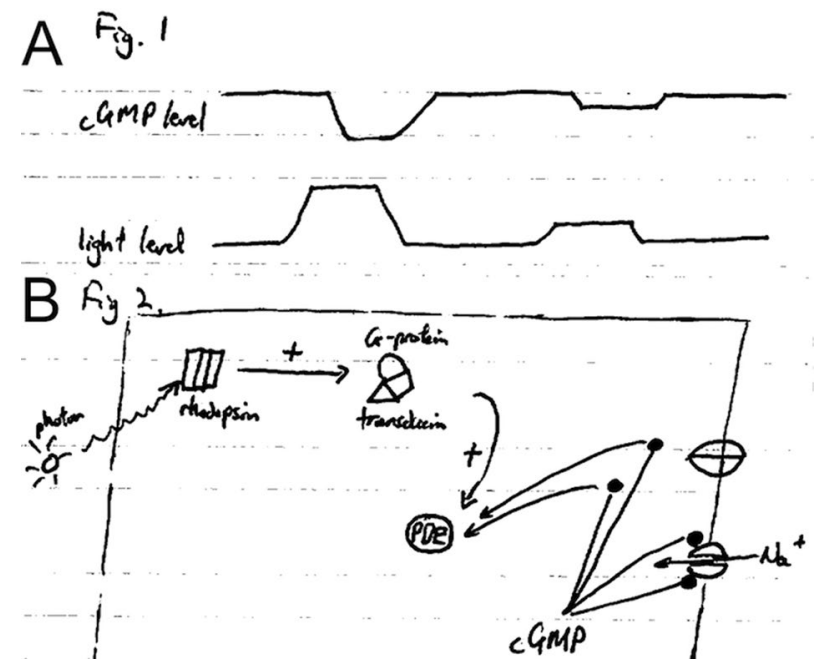

Figure 3. Drawings of the mechanism of phototransduction by Felix on exam 3. Panel A indicates the fluctuations of cGMP levels that could be measured in an experiment on plants with different light exposures. Panel B is a diagram of the molecular mechanism of phototransduction.

not identify the Methods in class, but he could within the research articles. Being unable to recognize or relate the Methods within the lecture to the mechanism he was learning affected his performance.

Felix eventually overcame the above challenges and used all the MACH components. The explanation he later gave during the interview addressed the regulatory mechanism of stomatal guard cells. This mechanism was familiar to Felix due to his previous research experience. During his oral interview, Felix used all of the MACH components for the mechanism. For instance, he put the explanation into a Context, "We were looking at drought tolerance because plants lose up to ninety percent of their water when they are open which is a really big problem if you are trying to grow plants in a desert" (Felix 2: 304-307). He was also able to connect his explanation of his mechanisms to the social context of agriculture. Along with this context, his oral explanation contained How and an analogy of a water wing as follows:

When a plant is undergoing stress from drought, it is going to release abscisic acid, which is a hormone that causes an increase, sorry a decrease in the amount of potassium of a stomatal guard cell, which causes water to flow out because water follows the potassium out of the cell, and once the water flows out of the cell, the guard cell shrinks and becomes flaccid and that is what closes the stomata. It is kinda like a water wing that kids use in pools.... Obviously a plant needs to be able to exchange gases with the environment. It needs to be able to take in $\mathrm{CO}_{2}$ and release oxygen and the only way it can do that is through stomata. And it is really important that it can be able to open and close it at will because one of the drawbacks of having basically a hole in your body is that you are going to be losing water and plants need water to survive and when they transpire, every minute they have their stomata open they are losing water and that is kind of trade off that plants have to figure out. (Felix 1: 268-290) 
Felix referred to entities, specific hormones, and ions, and their activity and organization in the stomatal guard cell (the How). Additionally, he used Analogy, by anthropomorphizing the plant and using need-based formulations when he said, "it needs to be able to." Furthermore, Felix included Methods:

\begin{abstract}
So one of the things we looked at in our research was the density of stomata cells on a leaf and how it correlated with how well it uses water or its water-use efficiency.... I got to count all the cells by hand, which was terrible because just within a week I think I counted 29,000 some cells, which included the stomata cells and the epithelia cells around it, and so I got to know stomatal density pretty well. (Felix 1: 310-329)
\end{abstract}

Felix was speaking from his experience in a research laboratory and connecting the mechanism to how one goes about studying stomatal cells. He used the MACH components in the way that biologists explain such content. Felix used the $\mathrm{M}$ factor to explain his chosen mechanism during his interview, as well as on exam 4, indicating regular usage of the $\mathrm{MACH}$ model after exam 3.

Petunia. Petunia was able to use all MACH components after being taught about the model and throughout the remainder of the semester for all of her mechanistic explanations. Unlike Felix, Petunia did not have a gradual transition to using the MACH components. She immediately used the components each time she was asked, as reflected in the following conversation:

Petunia: It isn't so much that I learned how to explain things through it but I learned how to refine my explanations. Or like, are they thorough enough and complete?

Interviewer: You felt like before you didn't have difficulty explaining?

Petunia: No, not really, but now it is more structured and I have more direction, it was something that I didn't know I was missing direction in. I never thought about how to explain things. (Petunia 1: 285-291)

Petunia used the MACH to help her create concise, well-structured, and complete explanations.

Petunia's problem set B, exam 4, and oral explanations were about a mechanism impacted by thalidomide, a drug that acts as a teratogen. By comparing these three explanations, one can see evidence of the MACH components and a changing explanatory structure. In the problem set, she explained,

[M] Thalidomide was discovered through a variety of experiments including one that involved the observation of rabbit eyes when exposed to thalidomide packets... [A] Thalidomide works like a faucet valve in early development... [C] Thalidomide is socially significant because it was originally used as a painkiller to ease symptoms of morning sickness in pregnant women, but it was found to be teratogenic.... [H] Thalidomide then intercalates into DNA, it is thought to do so at guanine residues. This intercalation leads to inhibition in the production of certain proteins. (Petunia, problem set B)
In addition to her writing, she included diagrams to illustrate cis-thalidomide entering a cell and intercalating DNA as an Analogy (Figure 4). Her explanation contained all the components and ample detail, but treated the MACH model as an ordered process rather than as a component model. The explanation was a list of factual statements rather than a fully integrated explanation. On reflection, Petunia noted what was happening: "It kind of seems like I ordered it in the MACH way and that is why it didn't line up" (Petunia 1: 575-576). Petunia was cognizant of a shift in how she was using and conceptualizing MACH. She reflected,

\begin{abstract}
So when we were first learning it was like-oh wait, so we have to go in that order so it has to be split up.... I feel like there is a jump from hey guys here is this tool to this is my personal use of it and you can incorporate it in various parts of an explanation, various forms within your explanations. So, it is taking that to actually using it. (Petunia 1: 364-370)
\end{abstract}

For Petunia, it was not until she practiced using the model that she combined the information and "various parts" into a coherent explanation with a flexible flow. For example, her exam 4 explanation read,

\begin{abstract}
[Thalidomide] has gone from being initially used to prevent nausea in pregnancy, to being the guilty cause of many babies' deformities, to being used today as a medicine for leprosy and multiple-myeloma.... Scientists used affinity purification beads to isolate thalidomide and its binding proteins. Scientist found that it binds with a strong specificity to cereblon (CRBN) protein. The second protein that was washed out in the affinity purification was DDB1. They found that DDB1 binds secondarily to thalidomide through associate with CRBN.... This leads to the conclusion that thalidomide's binding to CRBN and that protein's binding to DDB1 in turn led to a larger effect on ubiquitination by the E3 complex.... The mutation that scientists found is like a filter on a vacuum cleaner that allows it to still perform its function and pick up dust while preventing the intake of large or sharp objects that could harm the machine. Similarly mutated CRBN still forms the E3 complex, but does not cause bodily harm by binding to thalidomide. (Petunia, exam 4)
\end{abstract}

She improved her ability to communicate a large amount of information by mixing the components. She introduced her mechanism with the Context and then alternated between Methods and How to explain how an understanding of the entities and activities of the mechanism were supported by experiments conducted by scientists. Next, she used Analogy in her writing to make the mechanism comprehensible and in her model to illustrate how mutant CRBN failed to bind thalidomide (Figure 5). The remainder of her explanation blended each MACH component.

In addition to more interconnection, compared with her problem set explanation of the mechanism impacted by thalidomide, her exam 4 response focused heavily on the role of protein activity and the techniques used to establish binding between central proteins. Overall, Petunia used all of the $\mathrm{MACH}$ components immediately after the intervention, but it took time and practice for her to blend the components into a coherent explanation. 


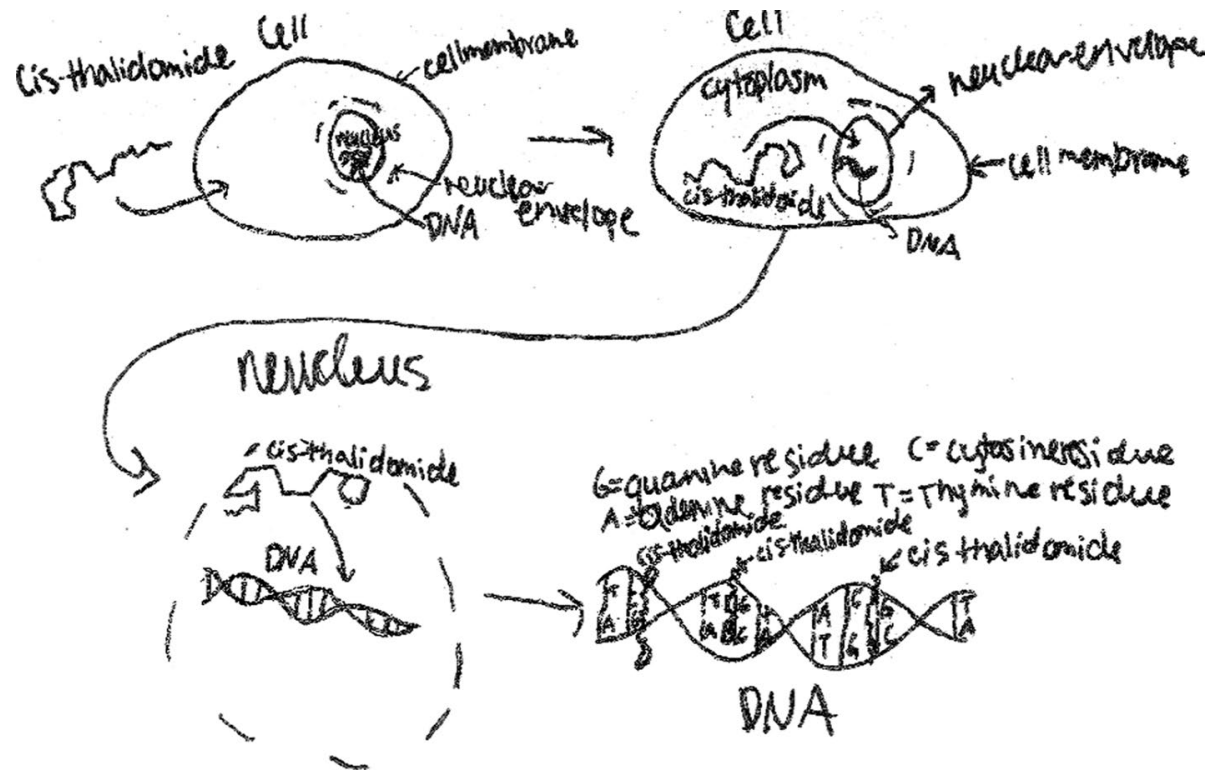

Figure 4. A drawing by Petunia from her problem set $\mathrm{B}$ response about the mechanism affected by thalidomide, a teratogen. The model depicts thalidomide intercalating with a portion of a DNA molecule within the nucleus. This artifact was retraced with black ink by the researcher to improve image quality.

\section{How and Why Did Students Think the MACH Model Was Useful?}

In exploring answers to research question 3, to understand how and why students found the MACH model to be useful, three key assertions were revealed from an inductive analysis of the explanations, artifacts, and interviews from the cases. All four students reported that the MACH model was useful when explaining mechanisms, since it helped them to self-monitor to achieve a deeper understanding of the mechanism they were explaining, to communicate explanations to their peers completely and concisely, and to recognize gaps or "holes" in their understanding of an explanation. Table 4 displays the findings that emerged from our exploratory study of the four case students and supportive excerpts from all four students, including Steve, who performed above the median on exam 3, and May, who scored below the median. Examples of each of the claims can be seen in the cases of Petunia and Felix presented below.

Felix. While it was clear that Felix changed the components he was including in his explanations, the question remained as to how he was using the MACH model to change his approach. For example, he stated, "Understanding a topic more thoroughly is certainly the biggest thing that comes out of the MACH model because it forces you to figure these things out just like the Methods" (Felix 2: 332-334). For Felix, using the MACH model helped him learn the mechanism to be explained, since it made explicit what he should understand. It allowed him to focus on specific pieces of information that would improve his explanation. He made this point explicit in the following quotation:

\begin{abstract}
I feel like the MACH model requires a lot more understanding of a topic than just explaining it to someone on the street.... So, it was kind of annoying having to go through all these things and making sure I understood, like, at certain levels or I meet certain requirements of the MACH model before I could proceed with other questions in homework.... Instead of taking that just, you know, surface level understanding, I wonder how this works on a much smaller scale system. (Felix 2: 161-177)
\end{abstract}

Felix used the model to monitor his understanding. It forced him to go deeply into the material when studying and to transcend into the lower scales of organization. However, Felix pointed out that he felt annoyed that he did not have enough time to explain at the level he wanted. The benefit of deepening understanding was not without drawbacks, as illustrated in the following conversation:

Felix: I think that is one of the downsides of the model when you go deeper into it ... the more you realize you don't understand as much as you think you do about a certain topic. And, I certainly had that experience with the cancer thing that we were doing for the poster. Like okay, I think I know how this works because it

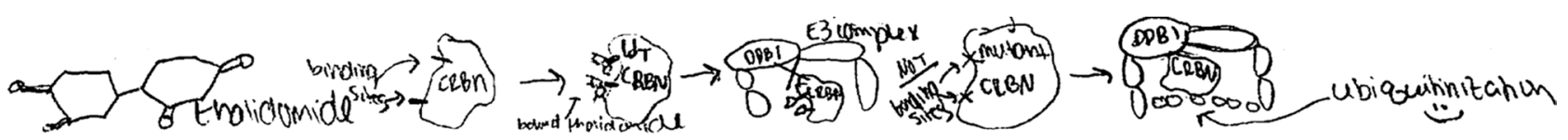

Figure 5. A drawing by Petunia from her exam 4 response to depict the mechanism affected by thalidomide. This model indicates that, when bound, thalidomide prevents a specific protein from entering the ubiquitination pathway, but thalidomide cannot bind to a functional mutant CRBN protein. 
Table 4. Assertions from analysis of four student cases about their use of the MACH model with sample quotes from each student interviewed

Self-monitor: Students practiced self-monitoring to reach a deeper level of understanding about the mechanism when they used the MACH model.

"So it was kind of annoying having to go through all these things and making sure I understood, like, at certain levels or I meet certain requirements of the MACH model before I could proceed with other questions in homework." (Felix 2: 168-172)

"The MACH model is just a cool way to check, check, check, check... It is a good tool for making sure that I check myself on it when I am explaining." (Petunia 1: 271-274)

"But it definitely helps me to consider all aspects of different mechanisms. Instead of just how it works, or the different parts of it, ... you have to go one step deeper and explain why it might happen, or how they [scientists] found out that it happens." (May 2: 65-72)

"I find it best for myself to put it in my own words then look at it with the MACH model and if I don't know the Methods or the How I can go back and find those." (Steve 1: 260-261)

Explain completely and concisely: Students communicated complete and concise explanations when using the MACH model.

"It provides a common ground for people to explain things... With the MACH model, I feel like one of the big outcomes is that it provides an even playing field for everyone ... Peers can communicate with one another at a much higher level." (Felix 2: 341-348)

"I just wanted to go on forever but the MACH model definitely facilitated me being efficient. If anything, it would get me through what I needed to while making sure it was a well-rounded explanation of what I had studied." (Petunia 1: 297-300)

"I would say that one of [the outcomes] is [I am] much more comprehensive in my explanations than I used to be by incorporating more elements into them ... making the explanation more meaningful by applying the Context and the Analogies. It forms a more complete explanation." (May 2: 136-143)

"I would say people [peers presenting posters] did use it because it kept them focused and helped them communicate a lot better, and get to the point a lot quicker." (Steve 1: 374-377)

Gap recognition: Students recognized gaps in their understanding of an explanation when using the MACH model.

"It's like the more I know, the more I realize that I don't know things, and that is kind of like really unsettling.... The first few times that I actually applied the MACH model I felt overwhelmed." (Felix 2: 238-249)

"You can read something and not know you are missing anything until you lay it all out and sometimes that is hard to do. And, a model like this you can see each part and break it down. And, this is the part where I might be a little weaker or less in length." (Petunia 1: 351-354)

"I can almost realize holes in my own explanation as I am explaining it to somebody else ... The MACH model helps bring it light a little bit more." (May 2: 81-88)

"It helps me see the holes in what I am looking at when I am explaining, when I am formulating an explanation.... and if I use the MACH model to look at those holes and think: Where am I? What is it that I am not comfortable with? I can go back to the research and know what I am looking for and then add that back and then think: Okay, does this sound right? Does this feel good? Do I feel like I am communicating effectively what I want to?" (Steve 1: 437-466)

was talking about apoptosis and programmed cell death, and I'm like-oh yeah, I have heard about that plenty. So I kind of put that off. But then, once I started reading into it and how it works and everything, I am like-um you know. This is a little over my head. I don't know if I understand it.... I feel like you are more uncertain knowing that you don't know it than before when it was just at that single level... Just having to use it [MACH] over and over again I feel like would make me feel more comfortable with it.

Interviewer: Okay, so what I am hearing is that by using it, it is actually revealing where those gaps are in your understanding ... while it is good that you are going deep you are also realizing how little....

Felix interrupts: Yeah, how little you know. Yeah, it is a little discomforting.... It's like the more I know, the more I realize that I don't know things, and that is kind of like really unsettling.... I don't know if that is a disadvantage of the MACH model or an advantage, you know, kind of motivating you to learn more, but certainly the first few times that I actually applied the MACH model I felt overwhelmed. (Felix 2: 207-249)

Felix recognized that once he had read and applied the $\mathrm{MACH}$ model he did not know as much as he previously thought. Felix's account was consistent with the illusion of explanatory depth. Through ineffective metacognition, he misjudged his level of knowledge based on familiarity.
Discouragement and discomfort came as he reevaluated his knowledge, and this helped him learn more about the topic he was pursuing. For Felix, the model was useful to help him self-monitor his understanding and to communicate and recognize explanatory gaps, which indicate facets of effective metacognition.

Petunia. Petunia's case offers insights into how a high-performing student might find the MACH model to be useful. She summarized her views succinctly during the interview:

Efficiency is the one word I would use to describe this
model's impact on me. Efficiency of explanation, effi-
ciency in analyzing that paper, and efficiency in learn-
ing without going through the stuff I know before I
can find the stuff I don't. (Petunia 1: 641-663)

Through use of the MACH model, Petunia developed an efficient way to communicate her mechanism concisely and completely, to analyze literature, and to monitor her understanding.

First, she used the model to ensure that her explanations contained all the MACH components. This is illustrated by the following quotations:

The MACH model for me was just really interesting because it laid it all out... I had those pieces but I never really thought about like why do I do this or what specifically do I say, like how does it work and why 
does it work, so the MACH model is just a cool way to check, check, check, check. Like that's cool. It works. It's formulaic, and I think it is a good tool for making sure that like I check myself on it when I am explaining stuff now. So people are coming to me with questions for finals, and I am like okay wait, did I do this in my explanation, okay they should understand it. So, it is kind of cool like it is a checklist making sure that is thorough. (Petunia 1: 267-277)

By "laying out" all the components, Petunia knew what parts should be made explicit in her explanation. She checked her explanations by using the MACH components as criteria to communicate completely and concisely. She used these criteria in other ways too.

Second, the MACH model stimulated her to search for and analyze information from the literature. For example, regarding her independent research project, she expressed the following:

It was just an interesting experience because personally it was just like my learning structure is like functional. I can read information and retain it, and give it back to you, but I never tried to like learn a certain [way].... It was a complicated paper and it took me a long time to piece apart and figure it out. I figured out what every diagram meant. That wasn't part of my presentation, but I figured out every single one. Like what was the significance? And, what did they do? And, what does this black dot mean? And, using the model for that really helped because I could piece out for each Method, for each part, for each How, for each diagram, like how did that go together, which on my own I was just like-this is too complicated and it would have probably taken longer. I am not going to lie to you because I would just scrounge up information instead of categorizing things. It was helpful. (Petunia 1: 641-655)

Thus, she found the MACH model to be useful as a heuristic to analyze a research paper and to connect the Methods, Analogies (e.g., "diagrams"), Context (e.g., "the significance"), and the How of a mechanism. In this sense, the model guided her reading and comprehension of the science article, since she was searching for how experts used the MACH components in the article to explain the mechanism. The model also helped her to self-monitor her own thinking and understanding of the discussed mechanism.

As in the case of Felix, the MACH model was useful in helping Petunia monitor her knowledge of her mechanism and to identify gaps in her understanding that required improvement. These features of metacognition are evident by the following quotations:

Petunia: Again like the efficiency, and it does help me, ... I use it as a check. So if I were to make an analogy, do I understand it well enough to do that? What else do I need to look into or research before I can do that? ... Where are the holes?

Interviewer: What do you mean by the "holes"?

Petunia: It is just like the holes in my knowledge of the topic or that understanding of what is happening because sometimes I can look at a page of notes and read and be like-okay, we are good. And then, we'll ask a test question and it's like-oh, that one specific thing just wasn't there.... If I imagine giving an all-inclusive explanation, I can find most parts that I am not sure on or that I am not as in-depth about. Again, using the model of, you know if I am going through the How and then, obviously I got to study that part. That is all.

Interviewer: So it helps you fill in those gaps, the holes you are talking about it. Is it a way to monitor?

Petunia: Almost like, you can read something and not know you are missing anything until you lay it all out and sometimes that is hard to do. And, a model like this you can see each part and break it down. And, this is the part where I might be a little weaker or less in length. (Petunia 1: 328-354)

Petunia used the MACH model to guide her identification of the parts she knew and the parts she did not know. She was able to identify gaps in her explanations and to help her focus on her weaker components. Her account suggests that the model aided her in making insightful judgments about her learning and self-monitoring her explanations. For Petunia, the MACH aided her to structure a complete explanation, to illuminate the "holes" in her knowledge, and to practice self-monitoring. As indicated by excerpts in Table 4, May and Steve, the other participants, echoed these ideas while being interviewed. Overall, to address research question 3, the four interviewed students found three main uses for the MACH as they progressed through the course work. They used the MACH model: to self-monitor understanding, to explain mechanisms fully and concisely, and to identify explanatory gaps.

\section{DISCUSSION}

\section{Summary of Results}

From our exploratory case studies, we were able to draw assertions about how the students we interviewed used MACH-model type components in their mechanistic explanations before and after a teaching intervention. To address research question 1: we found that the critical case students, unlike previously interviewed scientists (Trujillo et al., 2015), poorly integrated Methods when explaining biological mechanisms and revealed areas for potential growth before being introduced to the MACH model. To address research question 2: Felix and Petunia were able to incorporate missing components into their explanations but they varied in their attempts and the amount of practice needed before each succeeded. To address research question 3: the four interviewed students found the MACH model useful for helping them to self-monitor, communicate, and recognize gaps in their understanding.

\section{Limitations}

This work is presented as an exploratory phase of research, since it is the first reported transition of the MACH model into the classroom setting. Because of the qualitative nature of our research, which involved only a small number of volunteer students, the findings presented here may not hold up under scrutiny with well-designed teaching experiments in different settings; replication is needed, and readers 
should be cautious and not generalize claims that come from a case study, including this one. Our analysis focused on four students who do not, and were not intended to, represent the student body of our course. As with most exploratory case studies (Baxter and Jack, 2008), the purpose was not to produce generalizable claims but to deeply examine a particular feature in a highly contextualized setting in order to gain new insights. We were afforded this opportunity by using the MACH model as both a lens and teaching resource to understand mechanistic explanations made by biology students. Although further investigation is required to make extending claims, the findings presented contribute to generative knowledge.

\section{Explaining before Learning MACH}

In a previous study (Trujillo et al., 2015), we showed that seven biologists readily referred to the key and fundamental role that data, tools, and research procedures play in elucidating their particular mechanisms of interest. That is, their mechanistic explanations were rich in methodology. In sharp contrast, both Felix and Petunia particularly overlooked Methods in their explanations before exposure to the $\mathrm{MACH}$. Further research and discussion is required to fully understand the scope and nature of the reasons students have for omitting the $\mathrm{M}$ component, so that strategies can be devised to encourage more practitioners to link the content knowledge they teach to the research done to discover such knowledge. This finding constituted a strong motivation for the need to develop a guiding framework like the $\mathrm{MACH}$ model that could be used by instructors and students to facilitate the integration of Methods into mechanistic explanations. At the same time, this model would facilitate the incorporation of other components of explanation about mechanisms leading to a more expert-like, holistic, and informative explanation of a mechanism.

In light of the research presented here, some previously studied student difficulties related to mechanistic explanations are worth revisiting. First, Abrams and Southerland (2001) reported that primary and secondary students inappropriately addressed "how" explanations. In contrast, our research indicates that our case study students used the $\mathrm{H}$ component before the intervention. Second, our results show that students used $\mathrm{H}$ and explained entities, activities, and organization in a way that transcended levels of organization. These results go against findings from a number of reports that students have difficulty transcending levels of organization (Bahar et al., 1999; Marbach-Ad and Stavy, 2000; Duncan and Reiser, 2007; Talanquer, 2010). These discrepancies may be due to the different prompts used to elicit explanations and different education levels or experiences of the students.

Furthermore, our students, like biologists, integrated explanations of How something works with Analogies that often contained language about purpose, needs, and stories. Analogies have been viewed by some reports in the literature as indicative of misconceptions or alternative conceptions. However, biologists are known to readily use these analogies as a normal part of their repetoire of competencies (Zohar and Ginossar, 1998; Trujillo et al., 2015). When using the MACH model, students had the creative clearance to use less formal ways of explaining in addition to their mechanistic ways of explaining.

\section{Explaining after Learning MACH}

By the end of the course, both Petunia and Felix were involving all four MACH components, including Methods, in their explanation of biological mechanisms, but each worked to improve different aspects of their $\mathrm{MACH}$-informed explanations. After the teaching intervention, Felix had varied success in using the Methods component. With practice, he eventually came to use it in his later explanations. In our opinion, the sophistication with which a student incorporates the data, tools, and procedures into an explanation is one indicator of the insight that student has into a biological mechanism and how it was investigated by scientists. For an instructor, it is informative to recognize that Felix thought that the Methods were not presented in class, even when research tools and data were presented in lecture slides. This suggests that practice with MACH was needed by this student to guide him to reflect and use metacognition in relating research Methods presented in lecture to a mechanism. Knowing this, a biology teacher may wish to design specific $\mathrm{MACH}$-guided activities to teach students to relate research Methods to other key components of mechanistic explanations. Alternatively, an instructor may structure a curriculum with other approaches to encourage students to consider data and experiments, such as with the CREATE structure of Gottesman and Hoskins (2013).

For Petunia, an emergent difficulty was observed, since she included all the MACH components after the intervention but found interweaving the components into a coherent explanation to be a challenge. Future instructors could assist students to transition from thinking about $\mathrm{MACH}$ as a stepwise procedure to perceiving it as a way to achieve a holistic description. Educators who use the MACH may need to attend to the degree with which students integrate their explanations. Explicit recognition and instruction of this criterion may help students to explain as the scientists did in our previous study (Trujillo et al., 2015).

\section{Possible Uses of the MACH Model with Students}

In exploring answers to research question 3-Why do students think learning about the MACH model is useful, if at all? - we found that the MACH model impacted all four of our interviewed case study students' explanations by aiding their metacognition and their ability to self-monitor, to communicate complete and concise explanations, and to recognize gaps in their understanding. A possible reason for this finding is that students may be using the MACH model as an external cue to promote metacognition and prompt them to evaluate their knowledge. As put forward by Kruger and Dunning (1999), many students may not have enough baseline knowledge to make accurate judgments about their academic performance, so providing students with a guiding framework like the MACH model may provide a litmus test for students to efficiently evaluate their understanding for a wide variety of biological mechanisms.

On the other hand, improved monitoring may be related to the findings that explanations about facts, narratives, and procedures are less susceptible to illusions of explanatory depth when compared with explanations about natural phenomena (Rozenblit and Keil, 2002). Students who evaluate the Methods and Analogy components may use better 
metacognition when they reflect on and assess their explanatory knowledge of natural phenomena, since they are assessing their knowledge of facts, narratives, and procedures in combination, which therefore may be less susceptible to the illusion. It is possible that students find MACH useful for monitoring and recognizing gaps, because it taps into all the different explanatory types identified by Rozenblit and Keil (2002).

A tool such as the MACH model, which helped our interviewed learners to monitor their understanding and expose their illusions, may be further developed for use in both biology research and teaching. In research, the MACH could facilitate the writing of better-quality explanations about mechanisms in research documents such as grant proposals, research reports, and manuscripts. In teaching, $\mathrm{MACH}$ components could be used to indicate what is missing from a student's explanation of a biological mechanism, but educational research is needed to more carefully diagnose where and in what ways a student's explanation might be improved. The case of Petunia, who said, "It works. It's formulaic," helped us realize the need to further develop the MACH components into more than simply a formula for success in one course. Findings with MACH support a report by Grotz (2015), who claims that people use narratives to explain causation, whereas the $\mathrm{M}$ and $\mathrm{H}$ components of MACH are in line with reports that, at a deeper level, mechanisms describe what makes a causal relationship happen (Grotz, 2015; Yan and Talanquer, 2015). In particular, competent biology students might learn to recognize that some causal claims supported by experimental evidence ignore the underlying mechanism, meaning how or what drives it to work. For example, according to the findings in Table 3, Felix understood experiments in which light caused the stem of a plant to curve toward the light, as he mentioned the evidence for a phenomenon called phototropism. Evidence for phototropism was published by Charles Darwin in The Power of Movement in Plants in 1880 (Clase et al., 2010). But the mechanism was not understood until experiments were done in the 1920s to identify the plant hormone auxin as the signal that stimulates elongation of cells to drive bending of the stem (Sadava et al., 2008). Much research is currently focused on the phototropins (phot1 and phot2), the blue-light receptors in plants, to understand how they regulate phototropism by modulating auxin transport. Thus, Felix provided a weak explanation, because the experiment he described from Darwin's 1880 report was insufficient to explain what is now known about the biological mechanism for phototropism.

As they move through more advanced courses, to demonstrate competence, students may be encouraged with $\mathrm{MACH}$ to integrate biology research practices to explain putative biological mechanisms. To understand a biological mechanism that has become broadly accepted, students could integrate evidence from a series of experiments obtained from many different experimental procedures that today might even include gene expression knockdown and genome-editing experiments. In such a process, further development of $\mathrm{MACH}$ may help others gain a clearer set of expectations for students to understand the measurement of relevant variables, the adequacy of research tools and design, and how to make sense of and communicate findings from multiple experiments. Further research is needed to more carefully diagnose where and in what ways additional support is needed to help both low-performing and high-performing students integrate evidence from a series of experiments on biological mechanisms that are not directly observable. Whether or not use of the MACH model as an intervention helps students reduce overconfidence and become more metacognitive and realistic when assessing their understanding and whether or not this leads to large learning gains remain to be investigated.

\section{Implications of This Study}

Given the promising results of this study, the next steps would be to apply the MACH model to education research and education in other ways. First, for education researchers, this study should be expanded to understand the effects of the intervention in other populations and institutional settings to gauge the generalizability of the findings reported in this paper. Second, fruitful future investigations may focus on ways to encourage students' integration of research methods into their explanations of biological mechanisms. Researchers may start measuring the integration of components and language usage within an explanation in addition to deeply investigating the nature and quality of the explanations pertaining to each component. Third, researchers may investigate how MACH applies beyond biology. The MACH model holds potential for researchers to better understand the teaching and learning of explanations both within and beyond biology.

For biology educators, the MACH model is a promising metacognition tool that might help instructors meet a recommendation from Vision and Change (AAAS, 2011) to teach core competencies related to the practice of biology along with the core concepts that lend meaning to the biological explanations that students are learning. To further test the educational impact from use of the MACH model, educators may wish to create learning objectives, structure lectures and learning activities, and assess students around particular MACH components.

The work presented here may benefit both researchers and educators who wish to extend their work beyond explanations and the use of the MACH model. For instance, expert-derived component models may help researchers and educators clarify the tacit knowledge and skills from their disciplines to make ideas explicit and comprehensible for students and to more easily assess these ideas. Our findings highlight the potential interaction of component models to guide the development of metacognitive skills in students (Dunlosky and Metcalfe, 2008). This strategy may help address the burden of dual incompetence by aiding low-performing students to make accurate judgments of their understanding. As an additional contribution to education research in biology, this work illustrates the utility of exploratory case studies for understanding how an intervention impacts learning in the undergraduate biology classroom. As an available methodology, researchers may find this approach insightful for studying learning in a real-world setting when little is known about a topic. Overall, expert-derived component models like the MACH model and well-designed case studies hold promise for future research inquiries to improve undergraduate teaching and learning. 


\section{ACKNOWLEDGMENTS}

We thank Drs. Edward L. Bartlett and David Eichinger and members of our research groups, namely the Purdue International Biology Education Research Group (PIBERG) and the Visualization in Biochemistry Education (VIBE) Research Group, for their contributions to the progress of our study. We also thank our editor and reviewers for their valuable feedback to help improve an earlier draft of the article. We especially thank our case study students for willingly participating in this study. Some material presented here is based on research supported by the National Science Foundation under grants 0837229 and 1346567 . Any opinions, findings, and conclusions or recommendations expressed in this material are those of the authors and do not necessarily reflect the views of the National Science Foundation.

\section{REFERENCES}

Abrams E, Southerland S (2001). The how's and why's of biological change: how learners neglect physical mechanisms in their search for meaning. Int J Sci Educ 23, 1271-1281.

American Association for the Advancement of Science (2011). Vision and Change in Undergraduate Biology Education: A Call to Action, Washington, DC: National Academies Press.

Bahar M, Johnstone AH, Hansell MH (1999). Revisiting learning difficulties in biology. J Biol Educ 33, 84-86.

Baxter P, Jack S (2008). Qualitative case study methodology: study design and implementation for novice researchers. Qual Rep 13, 544-559.

Bonifacino JS, Glick BS (2004). The mechanisms of vesicle budding and fusion. Cell 116, 153-166.

Bray-Speth E, Shaw N, Momsen J, Reinagel A, Le P, Taqieddin R, Long T (2014). Introductory biology students' conceptual models and explanations of the origin of variation. CBE Life Sci Educ 13, 529-539.

Clark LA, Watson D (1995). Constructing validity: basic issues in objective scale development. Psychol Assess 7, 309.

Clase KL, Gundlach E, Pelaez NJ (2010). Calibrated peer review for computer-assisted learning of biological research competencies. Biochem Mol Biol Educ 38, 290-295.

Duncan RG, Reiser BJ (2007). Reasoning across ontologically distinct levels: students' understandings of molecular genetics. J Res Sci Teach 44, 938-959.

Dunlosky J, Metcalfe J (2008). Metacognition, London: Sage.

Flyvbjerg B (2006). Five misunderstandings about case-study research. Qual Inq 12, 219-245.

Garvin-Doxas K, Klymkowsky MW (2008). Understanding randomness and its impact on student learning: lessons learned from building the Biology Concept Inventory (BCI). CBE Life Sci Educ 7, 227-233.

Gottesman AJ, Hoskins SG (2013). CREATE cornerstone: introduction to scientific thinking, a new course for STEM-interested freshmen, demystifies scientific thinking through analysis of scientific literature. CBE Life Sci Educ 12, 59-72.
Grotz TA (2015). Causal reasoning: what is it and how does it relates to science teaching and learning? In: Encyclopedia of Science Education, ed. R Gunstone, New York: Springer, 142-146.

Kruger J, Dunning D (1999). Unskilled and unaware of it: how difficulties in recognizing one's own incompetence lead to inflated self-assessments. J Pers Soc Psychol 77, 1121.

Liebler J (2007). The Inner Life of the Cell, Cambridge, MA: Harvard University/XVIVO, animation.

Lincoln YS, Guba EG (1985). Naturalistic Inquiry, Newbury Park, CA: Sage.

Marbach-Ad G, Stavy R (2000). Students' cellular and molecular explanations of genetic phenomena. J Biol Educ 34, 200-205.

Roediger HL (1996). Memory illusions. J Mem Lang 35, 76-100.

Rozenblit L, Keil F (2002). The misunderstood limits of folk science: an illusion of explanatory depth. Cogn Sci 26, 521-562.

Sadava DE, Hillis DM, Heller HC, Berenbaum M (2008). Life: The Science of Biology, 9th ed., Sunderland, MA: Sinauer/Freeman.

Schönborn KJ, Anderson TR (2009). A model of factors determining students' ability to interpret external representations in biochemistry. Int J Sci Educ 31, 193-232.

Talanquer V (2010). Exploring dominant types of explanations built by general chemistry students. Int J Sci Educ 32, 2393-2412.

Tellis WM (1997). Application of a case study methodology. Qual Rep 3, 31-19.

Thomas DR (2006). A general inductive approach for analyzing qualitative evaluation data. Am J Evaluation 27, 237-246.

Todd A, Kenyon L (2015). Empirical refinements of a molecular genetics learning progression: the molecular constructs. J Res Sci Teach, doi:10.1002/tea.21262.

Trujillo CM, Anderson TR, Pelaez NJ (2014). A Tetrahedral Version of the MACH Model for Explaining Biological Mechanisms, Purdue University: PIBERG Instructional Innovation Materials. http: / / docs.lib.purdue.edu/pibergiim/1 (accessed 7 February 2016).

Trujillo CM, Anderson TR, Pelaez NJ (2015). A model of how different biology experts explain molecular and cellular mechanisms. CBE Life Sci Educ 14, ar20.

van Mil MHW, Boerwinkel DJ, Waarlo AJ (2013). Modelling molecular mechanisms: a framework of scientific reasoning to construct molecular-level explanations for cellular behaviour. Sci Educ 22, 93-118.

Wright LK, Fisk JN, Newman DL (2014). DNA $\rightarrow$ RNA: what do students think the arrow means? CBE Life Sci Educ 13, 338-348.

Yan F, Talanquer V (2015). Students' ideas about how and why chemical reactions happen: mapping the conceptual landscape. Int J Sci Educ 37, 3066-3092.

Zierath JR, Lendahl U (2013). Machinery Regulating Vesicle Traffic, a Major Transport System in Our Cells. www.nobelprize.org/nobel prizes/medicine/laureates/2013/advanced-medicineprize2013 .pdf (accessed 23 October 2013).

Zohar A, Ginossar S (1998). Lifting the taboo regarding teleology and anthropomorphism in biology education-heretical suggestions. Sci Educ 82, 679-697. 